\title{
Does the Quality of Source Notes Matter? An Exploratory Study of Source-based Academic Writing
}

\author{
Heike Neumann, Sarah Leu, Kim McDonough, Leslie Gil, \\ $\mathcal{E}$ Bonnie Crawford
}

Integrated writing tasks have increased in popularity in second language writing classrooms. Extensive research on these tasks has examined the challenges that students face when completing such tasks. One significant challenge is the transformation of source language use when students integrate source information into their own essays. However, little is known about the relationship between students' source notes and the quality of the essays that they produce. This exploratory study examined this issue by investigating the relationship between characteristics of English for academic purposes $(E A P)$ students' notes $(N=24)$ and their essay scores. The students' notes were coded in terms of how they appropriated information from the source texts using four categories: copied, copied with changes, copied with gaps, and paraphrased. A multiple linear regression revealed that essay scores were predicted by the degree to which the students transformed source language and avoided copying. The implications of these findings for second language (L2) writing pedagogy and assessment are discussed.

Les tâches de rédaction intégrée deviennent de plus en plus populaires dans les classes de rédaction en seconde langue. Ces tâches ont fait l'objet de nombreuses recherches qui ont étudié les défis auxquels font face les étudiants lorsqu'ils les exécutent. Un défi de taille est la transformation de l'utilisation de la langue source lorsque les étudiants intègrent l'information tirée des sources dans leurs rédactions. Cependant, on ne sait pas grand chose sur la relation entre les notes des étudiants provenant des sources et la qualité des rédactions qu'ils produisent. Cette étude exploratoire s'est intéressée à ce problème étudiant la relation entre les caractéristiques des notes des étudiants dans les cours d'anglais académique $(N=24)$ et les notes obtenues pour leurs rédactions. Les notes des étudiants ont été classées en quatre catégories selon la façon dont ils s'appropriaient l'information des textes sources : copiées, copiées avec des changements, copiées avec des lacunes et paraphrasées. Une régression multiple linéaire a révélé que les notes obtenues pour les rédactions étaient prédites par le degré auquel les étudiants avaient transformé la langue source et avaient évité de copier. On discute des implications de ces résultats pour la pédagogie et l'évaluation de la rédaction en langue seconde (L 2).

Keywords: source-based writing; integrated writing tasks; notes; planning; patchwriting 
Recent decades have seen an increased interest in integrated writing tasks (IWTs) or source-based writing tasks. Depending on the task parameters, these tasks require students to read at least one source text but can involve multiple source texts or even oral input. These tasks have increased in popularity because the process in which writers have to engage is seen as similar to academic writing tasks in the disciplines (Cumming, 2013). As Plakans' $(2008,2009 \mathrm{~b})$ research showed, the process of completing such a task essentially involves the following steps:

- reading (or listening to) the source text(s) and understanding the presented information

- choosing a position on how to respond to the assigned writing topic

- selecting and organizing ideas from the source(s)

- integrating ideas from the source with writer's own ideas

- using source text information in ways that avoid plagiarizing

The challenge of integrating source information by transforming source language use appropriately (and not copying or overusing it), in particular, has received significant attention in prior research. Howard (1992) coined the term patchwriting to refer to instances of "copying from a source text and then deleting some words, altering grammatical structures, or plugging in one-forone synonym substitutes" (p. 233). Research in both first and second language (L2) writing contexts with novice to advanced writers has documented the prevalence of patchwriting in texts that rely on the information from outside sources (Cumming et al., 2016; Davis, 2013; Flowerdew \& Li, 2007; Howard et al., 2010; Neumann et al., 2019; Pecorari, 2003, 2006, 2010; Wette, 2010), and it is seen as part of the process of developing academic writing skills. However, L2 writers face additional challenges in this regard as they may not have sufficient note-taking skills and strategies (Pecorari, 2013; Plakans, 2009b) and therefore overly rely on patchwriting (Cumming et al., 2016; Currie, 1998; Gebril \& Plakans, 2009; Li \& Casanave, 2012; Plakans \& Gebril, 2012, 2013; Wolfersberger, 2013). Research into patchwriting in written texts generally involves the following approach: Information and language use in the students' texts is compared to the (known) source texts students used during the writing process. First, references to the ideas of the source text(s) are identified and then coded as either cited or not cited (i.e., has the source been acknowledged). Then, language used to integrate these ideas is analyzed and coded. Although researchers' labels vary, they generally correspond to Gebril and Plakans' (2013) categories: indirect source use (paraphrases and summaries of source information) and verbatim or direct source use (strings of words copied directly from the source). Using this approach, researchers can closely examine the relationship between source text(s) and the texts produced during an IWT and examine the reasons for students' overreliance on patchwriting. Studies have shown that L2 writers have trouble comprehending the source text information (Asención Delaney, 
2008; Esmaeili, 2002; Neumann et al., 2019; Plakans, 2009a; Sawaki et al., 2013), identifying important ideas (Plakans \& Gebril, 2013), and selecting ideas for inclusion in their own texts (Neumann et al., 2019). In addition, research has discovered that L2 writers do not always rely on effective strategies. They are good at using the source texts to obtain ideas for their own writing (Neumann et al., 2019; Pecorari, 2003; Plakans, 2009b); however, they do not always check whether they have paraphrased the information appropriately (Pecorari, 2003; Plakans, 2009b) and have difficulty in presenting the source information accurately (Neumann et al., 2019).

This line of research has provided great insight into whether and how English L2 writers linguistically modify source text language while integrating source information into their texts when they have access to the sources while writing; less is known, however, about how English L2 writers use preplanned source notes. On standardized test with IWTs, such as the TOEFL iBT or the CAEL, students read (and listen to) the source texts immediately prior to performing the writing tasks and therefore do not have much need for source notes. However, in classroom-based assessment contexts, students may draw on notes based on the source texts instead of the source texts directly. The same applies to real-life academic writing tasks in content courses. In fact, planning and note-taking form part of the naturalistic process of writing from sources (e.g., McCulloch, 2013), but there has been very little research on the use of notes during IWTs specifically. Previous writing research has looked at planning in preparation for writing but not note-taking in particular, and the issues examined in this line of research will be discussed below. However, the role that the students' notes play and how students' level of source-language transformation in notes relates to their writing performance have not been investigated. The current study has been designed to examine the relationship between the degree of source-language modification in notes and the overall quality of source-based essays.

\section{Research on Planning and Note-Taking}

Many assessments that use IWTs, such as the TOEFL and CAEL, include recommended or dedicated time for prewriting planning (Payant et al., 2019), which is an essential component in most contemporary models of the writing (Limpo \& Alves, 2018) and gives the writer a small degree of control over their creative process. Research into the effects of prewriting conditions on performance has yielded contradictory findings. Some studies have found that planning positively influences some aspects of writing, such as online planning (Ong, 2014). In contrast, other studies have reported no effects on lexical or syntactic complexity and negative effects on fluency (Johnson et al., 2012) or found no significant relationship (Payant et al., 2019). In an effort to understand these results, researchers have explored other writing-related variables including planning time (Ong, 2014), planning strategy (Kellogg, 
1990), task complexity (Ong \& Zhang, 2010), interruptions (Foroughi et al., 2014), writing anxiety (Payant et al., 2019), motivation (Ojima, 2006), and reading ability (Payant et al., 2019), while also manipulating planning time (Kellogg, 1990; Ong, 2014; Ong \& Zhang, 2010) and other pre-task planning conditions (Foroughi et al., 2014; Johnson et al., 2012; Kellogg, 1990; Ong, 2014; Payant et al., 2019). However, few studies have explored whether the nature and quality of prewriting notes has a significant impact on the final text, especially in the case of IWTs.

One of the first studies to consider the quality of student notes was Ojima's (2006) comparison of opinion compositions written by three L2 English learners: Concept mapping had positive effects on complexity, fluency, organization, and global quality measures. Upon closer examination, however, the participants' use of the concept map was extremely varied: One participant used the concept map as an idea generation web; another's functioned similarly to an outline or draft with topic sentences, examples, and conclusions, while the third participant did not draw a concept map at all (Ojima, 2006). Furthermore, these differences continued into the writing process: The first student selected a few ideas from her concept map for her final composition; the second student included the majority of the concept map content, and the third student showed very few signs of applying or connecting the prewriting activity to the final text. Ojima (2006) concluded that these individual differences may be responsible for the writing outcomes and recommended increased teacher support and feedback while learning and practising planning strategies.

This interpretation has been supported by Chai (2006) and, more recently, Joaquin, Kim, and Shin (2016). Chai (2006) examined opinion essays from primary and secondary students in Western Canada by categorizing the plans into five levels of elaboration based on a rater's holistic assessment among other criteria included in her study. Although few students made elaborate plans, she reported an almost step-wise positive relationship between the amount of elaboration and mean writing scores in each grade; however, there was only a significant difference between levels of elaboration in Grade 4 (Chai, 2006). Joaquin and colleagues (2016) analyzed the L2 planning and writing of opinion essays by university students. Writing plans were categorized by a rater into three groups: minimal, standard, or elaborate. The study found a significant relationship between writing plans and the essay scores, with the elaborate group scoring higher on their essays than the minimal group. Other research has shown that the number of ideas generated in a prewriting exercise is strongly correlated with the quality and length of the final summary text for L2 learners (Abrams \& Byrd, 2016) and that the amount of detail in a prewriting concept map is correlated with writing performance on short opinion or personal compositions (Liu, 2011).

Payant and her colleagues (2019) examined whether students' quantity of notes and note-taking strategies predicted their IWT writing performance. 
The participants' approach to note-taking was categorized as outlining, listing, free-writing, webbing, drafting, or a combination of these strategies. The prewriting plans were further categorized as (very) short, standard, or elaborate. Although they identified several statistically significant variables that predicted participants' writing performance (namely writing anxiety, self-efficacy, and reading and listening comprehension), neither planning strategies nor degree of note-taking detail predicted IWT performance.

Since, to our knowledge, there is no research on the analysis of source language use in notes, we examined research on IWTs that studied the relationship between the level of source language use modification in essays and essay scores. Gebril and Plakans' research (Gebril \& Plakans, 2009, 2013; Plakans \& Gebril, 2013) clearly indicates that essays with higher scores are characterized by higher levels of linguistic modification of source language use, whereas lower level essays show higher degrees of copying of source language use. Although Weigle and Parker's (2012) study did not find a statistically significant relationship between source language use and essay scores, they did identify a tendency for greater source language borrowing in essays with lower scores. It stands to reason, therefore, that a similar relationship may exist between the level of linguistic modification to source language use on source notes and essay scores.

To summarize, research has indicated that there is a relationship between planning and writing performance. Findings in the planning research have been somewhat inconsistent, leading researchers to investigate moderating variables that may influence the writing processes. Among these, the quality or elaborateness of the planning notes as examined in the aforementioned studies has been shown to predict performance, indicating that a study focusing exclusively on defining the characteristics of notes and how the quality of prewriting planning notes affects writing performance is necessary. Moreover, with the exception of Payant and colleagues (2019), previous studies have analyzed prewriting notes in stand-alone writing tasks rather than source-based IWTs; as a result, these findings may not be generalizable to IWT assessments because of the differences in the composing process between source-based and non-source-based writing tasks (Plakans, 2008). Evidence from research into IWTs suggests that the level of linguistic modification in source-based essays is related to essay scores; however, the relationship between linguistic modification to source language in source notes and essay scores has not been examined. Given their increased popularity, an inquiry specific to IWT source notes is warranted, and the current study examined this issue by investigating the following research question: Is the level of linguistic modification of source language use in source notes related to the overall quality of source-based essays? 


\section{Method}

\section{Research Context}

The study took place in the second of two courses in a general English for academic purposes (EAP) program at an English-medium university in Canada. At this university, students who are admitted with TOEFL iBT scores of 75 to 89 or equivalent may be required to take up to two EAP courses as part of their degree program, depending on their performance on an in-house placement test. The second of these EAP courses focuses on the development of reading, writing, vocabulary, and grammar skills. Each unit contains theme-based academic readings, and the core readings are accompanied by exercises that focus on developing reading comprehension and the lexical repertoire of students. In terms of writing, each unit has a different focus. The early units focus mainly on paraphrasing, synthesizing, and summarizing skills, which students apply in the later units, where they are asked to write source-based academic essays. The sources that students work with for these essays all come from the selection of materials prepared for the course and are made available to students along with all other pedagogical materials through a custom coursepack. Some of the reading texts come from EAP materials (e.g., Schmitt \& Schmitt, 2005; Williams, 2012), but others are adapted from authentic sources (e.g., Sandel, 2012). Adaptation involved mainly shortening sources to a more manageable length and focusing on aspects most relevant to the thematic content of the unit. In addition to class assignments, students write two midterms and one final exam. The second midterm and the final exam both require students to write source-based essays within a time limit of three hours. For these two exams, students are provided with a reading list with six to seven sources from the coursepack two weeks prior to the scheduled exam date. The sources are associated with two writing topics that are given to students on the day of the exam, and students choose one of these topics to write their essay. Teachers are allowed and encouraged to discuss the sources on the reading list with their students and support students in the completion of note sheets for the source texts following a note-taking sheet template designed by instructors in the EAP program (see Appendix A). Although students do not receive formal note-taking instruction as part of the course, instructors can draw on the following strategies to help their students take effective source notes: (1) review the guidelines for taking sources notes (e.g., the recommendation to paraphrase instead of copying language from the source and write point-form rather than sentences or paragraphs) and (2) discuss sample source note sheets and sample essays in the coursepack to illustrate how information might be converted from notes to the essay.1 On the day of the exam, students are allowed to bring one note sheet per source and an English-only paper dictionary. At the end of the exam, students have to submit their note sheets along with the essay exam. 


\section{Procedure and Participants}

The data for the current study were collected as part of a study designed to investigate the challenges students face when integrating information from outside sources into their own essays (Neumann et al., 2019). For that study, the final exams and note sheets of all students who had agreed to participate in the study were collected. Both the essays and note sheets were typed and verified by research assistants to facilitate analysis; minor spelling errors were corrected at this point to obtain machine-searchable typed essays and note sheets. For reasons of illegibility or incomprehensibility, it was not possible to type all note sheets. For the current study, only essays written in response to one of the two topics (related to advertising) for which note sheets could be typed were included in the data set. Based on these criteria, the essays and note sheets of 24 students (10 female and 14 male) were selected for analysis. The students who wrote these essays and notes ranged in age from 17 to $39(M=23.1, S D=$ 5.8 ) and came from a variety of first language backgrounds, with French (32\%), Chinese $(28 \%)$, and Arabic (12\%) as the most common. Since students were registered in a general EAP course, they were enrolled in programs in different academic fields: business (38\%), engineering and computer science $(29 \%)$, social sciences $(17 \%)$, fine arts $(13 \%)$, and humanities $(4 \%)$.

\section{Data Analysis}

All 24 essays were rated by two raters using an analytical rating scale with separate assessment criteria for content, organization, and language use (see Appendix B). This scale is based on the established EAP program rating scale, which we modified in the following two ways to fit the needs of the study: (1) adding subscores for the different criteria and (2) eliminating the mechanics/ punctuation criterion. Since minor spelling errors were corrected when essays were typed to make the texts machine-searchable, it was impossible to assess students' original spelling, one of the key criteria on the scale under mechanics. Each criterion on the scale was scored out of 10 for an overall score of 30 . The raters were experienced instructors of the course in which the study took place. To determine interrater reliability, the intra-class coefficient (ICC) was calculated using a two-way mixed model to determine absolute agreement $(I C C=.65, p=.009)$.

To analyze the note sheets, we developed our own coding scheme that was based on an initial analysis of the note sheets and refined through discussion. The goal of our coding scheme was to capture the level of patchwriting in students' notes by analyzing the language that students used to record the source information on their note sheets and how that language related to the language used in the original source. In our analysis, we focused on the level of copied and paraphrased language in the students' notes. Our final coding scheme included four categories (copied, copied with changes, copied with gaps, and paraphrased), which are described and illustrated with examples in 
Table 1. These codes were applied to phrases, whose length was determined by changes in the students' language use style. Did the student, for example, switch from paraphrasing to copying with gaps? During the initial stages of analysis, we discovered that the vast majority of words in the vocabulary and quotations sections of the note-taking template (see Appendix A) belonged to the copied coding category. Including these sections, hence, artificially inflated the word count for the copied code for those sheets. We decided, therefore, to only include the text in the main idea and key supporting ideas fields of the note-taking templates, where we could expect to see actual student notes in our analysis. For each student's note sheets, the total number of words in the two analyzed fields on the note sheets coded as belonging to each of the four categories was recorded. The fifth researcher coded all of the note sheets and a paid research assistant coded 15\% of the note sheets to assess the reliability of our coding scheme. Cohen's kappa was calculated for all four variables, and values ranged from .65 for paraphrased to .92 for copied with changes. To examine the relationship between the language use on these note sheets and the students' performance on the IWT, we calculated Pearson correlation coefficients and conducted a multiple linear regression.

Table 1

Coding Categories for Note Sheets with Examples

\begin{tabular}{|c|c|c|c|}
\hline Code & Description & $\begin{array}{l}\text { Original passage from source } \\
\text { with information/language used } \\
\text { in example underlined }\end{array}$ & $\begin{array}{l}\text { Example with } \\
\text { reference to } \\
\text { source information } \\
\text { underlined }\end{array}$ \\
\hline Copied & $\begin{array}{l}\text { Source language } \\
\text { is copied from } \\
\text { source, possibly } \\
\text { with minor correct } \\
\text { or incorrect } \\
\text { changes or use of } \\
\text { abbreviations }\end{array}$ & $\begin{array}{l}\text { We live in a time when almost } \\
\text { everything can be bought and } \\
\text { sold. (Sandel, 2012) }\end{array}$ & $\begin{array}{l}\frac{\text { Everything can }}{\text { be bought/sold }} \\
\text { (Student } 672 \text { ) }\end{array}$ \\
\hline $\begin{array}{l}\text { Copied with } \\
\text { changes }\end{array}$ & $\begin{array}{l}\text { Source language } \\
\text { is copied with } \\
\text { changes in word } \\
\text { order, possibly } \\
\text { with minor correct } \\
\text { or incorrect } \\
\text { changes or use of } \\
\text { abbreviations }\end{array}$ & $\begin{array}{l}\text { Consumer advocates, } \\
\text { government agencies and } \\
\text { other critics have accused } \\
\text { marketing of harming consumers } \\
\text { through high prices, deceptive } \\
\text { practices, high-pressure selling, } \\
\text { unsafe products, planned } \\
\text { obsolescence and poor service } \\
\text { to disadvantaged consumers. } \\
\text { (Armstrong et al., 2012, pp. 80- } \\
\text { 81) }\end{array}$ & $\begin{array}{l}\text { Marketing is } \\
\text { harmful for } \\
\text { consumers because } \\
\text { of high prices, poor } \\
\text { service and unsafe } \\
\text { products. (Student } \\
644)\end{array}$ \\
\hline
\end{tabular}




\begin{tabular}{|c|c|c|c|}
\hline $\begin{array}{l}\text { Copied with } \\
\text { gaps }\end{array}$ & $\begin{array}{l}\text { Language is } \\
\text { copied from } \\
\text { source with gaps, } \\
\text { but words are left } \\
\text { out or replaced by } \\
\text { symbols }\end{array}$ & $\begin{array}{l}\text { Critics charge that there are } \\
\text { too many intermediaries, that } \\
\text { intermediaries are inefficient or } \\
\text { that they provide unnecessary or } \\
\text { duplicate services. (Armstrong et } \\
\text { al., 2012, p. 81) }\end{array}$ & $\begin{array}{l}\text { too many } \\
\text { intermediaries } \\
\text { (unnecessary/ } \\
\text { duplicates service) } \\
\text { (Student 663) }\end{array}$ \\
\hline Paraphrased & $\begin{array}{l}\text { Source information } \\
\text { is rendered in } \\
\text { students' own } \\
\text { words but can } \\
\text { contain key terms } \\
\text { from the original } \\
\text { source }\end{array}$ & $\begin{array}{l}\text { Putting a price on the good } \\
\text { things in life can corrupt them. } \\
\text { That's because markets don't } \\
\text { only allocate goods; they } \\
\text { express and promote certain } \\
\text { attitudes toward the gods being } \\
\text { exchanged. Paying kids to read } \\
\text { books might get them to read } \\
\text { more, but might also teach them } \\
\text { to regard reading as a chore } \\
\text { rather than a source of intrinsic } \\
\text { satisfaction. (Sandel, 2012) }\end{array}$ & $\begin{array}{l}\text { If we put everything } \\
\text { on sale, it loses its } \\
\text { value, like giving } \\
\$ 2 \text { to kids for them } \\
\text { to read a book, it is } \\
\text { going to make the } \\
\text { kids read but they } \\
\text { will associate read } \\
\text { as a way to have } \\
\text { money and not as } \\
\text { an entertainment. } \\
\text { (Student } 662 \text { ) }\end{array}$ \\
\hline
\end{tabular}

\section{Results}

The 24 essays included in this study ranged in length from 406 to 803 words, with a mean length of 552.3 words $(S D=105.9)$. They were rated on a 10-point scale by two raters on three criteria (content, organization, and language use) with an overall score out of 30 . Mean overall scores of the two raters for each essay were used for further analysis. The mean overall score for all 24 essays was $21.8(S D=1.97)$.

The quantity of students' notes varied greatly, with the overall word count in the analyzed sections of students' note sheets (i.e., the main idea and key supporting ideas fields of the note-taking templates, see Appendix A) ranging from 123 to 1,139 words $(M=515.5, S D=311.99)$. Language use on the note sheets was analyzed using four coding categories: copied, copied with changes, copied with gaps, and paraphrased. Again, the frequency with which students' language use reflected these four categories varied greatly. Table 2 displays the total number of words, means, and standard deviations for all four categories (percentages have been rounded). As is clearly evident, paraphrased was most frequent with $48 \%$ of all words in the notes corpus belonging to that category. The least frequent category was copied with changes, which accounted for only $4 \%$ of all language use in the notes corpus and was not used by all students (minimum value of 0 ). 
Table 2

Descriptive Statistics for Language Use on Note Sheets

\begin{tabular}{lllll}
\hline & Copied & $\begin{array}{l}\text { Copied with } \\
\text { changes }\end{array}$ & $\begin{array}{l}\text { Copied with } \\
\text { gaps }\end{array}$ & Paraphrased \\
\hline $\begin{array}{l}\text { Total (words / \%) for } \\
\text { notes corpus }\end{array}$ & $2,543 / 22 \%$ & $513 / 4 \%$ & $3,058 / 26 \%$ & $5,722 / 48 \%$ \\
$\begin{array}{l}\text { Maximum (words / \%) } \\
\text { per set of notes* }\end{array}$ & $335 / 39 \%$ & $161 / 20 \%$ & $556 / 68 \%$ & $670 / 92 \%$ \\
$\begin{array}{l}\text { Minimum per set of } \\
\text { notes (words / \%) }\end{array}$ & $15 / 3 \%$ & $0 / 0 \%$ & $16 / 4 \%$ & $11 / 9 \%$ \\
$\begin{array}{l}\text { Mean (words / \%) for } \\
\text { notes corpus }\end{array}$ & $106 / 21 \%$ & $21.38 / 5 \%$ & $127.42 / 26 \%$ & $238.4 / 46 \%$ \\
$\begin{array}{l}\text { Standard deviation } \\
\text { (words) for notes } \\
\text { corpus }\end{array}$ & 85.93 & 33.97 & 123.41 & 164.25 \\
\hline * Number of words and percentage can refer to different students' sets of note sheets
\end{tabular}

Prior to conducting the multiple linear regression, we calculated Pearson correlation coefficients to select the variables for inclusion in the regression model. Table 3 displays the Pearson correlation coefficients between the overall essay scores and the four language use variables.

Table 3

Pearson Correlation Coefficients between the Overall Essay Score and Language Use Categories

\begin{tabular}{lll}
\hline & $r$ & $p$ \\
\hline Copied & .039 & .855 \\
Copied with Changes & -.457 & .025 \\
Copied with Gaps & .000 & .999 \\
Paraphrased & .296 & .296 \\
\hline
\end{tabular}

Following Plonsky and Oswald's (2014) categorizations, we decided to include those variables with small $( \pm .25)$ or larger correlations in our regression model. Therefore, the variables copied with changes and paraphrased were included in the regression model as predictor variables, with the overall essay score as the outcome variable. The multiple regression model was statistically significant $\left[R^{2}=.363\right.$, adjusted $\left.R^{2}=.302, F(2,21)=5.979, p=.009\right]$. The adjusted $R^{2}$ indicates that this model accounts for about $30 \%$ of the variance in the overall essay score, pointing towards a meaningful relationship between students' notes characteristics and their performance on the essay task. Table 4 presents the unstandardized $(B)$ and standardized beta coefficients $(\beta)$ for this model. The statistically significant standardized beta coefficients indicate a positive correlation between paraphrased language use and the overall score 
and a negative correlation between copied with changes language use and the essay score.

Table 4

Multiple Linear Regression Coefficients

\begin{tabular}{lllll}
\hline & $B$ & Standard error & $\beta$ & $p$ \\
\hline Copied with Changes & -.031 & .010 & -.535 & .007 \\
Paraphrased & .005 & .002 & .400 & .035 \\
\hline
\end{tabular}

To illustrate the findings from the linear regression with writing samples, Table 5 presents excerpts from two student essays with the corresponding source notes. Excerpt 1 stems from Student 663's essay, which received the highest total score (25.5/30), and the student's notes contain a low percentage of language copied from the source text (words copied with changes $0.5 \%$, total words copied for all three categories: $21.6 \%$ ) and a high percentage of paraphrased notes (78.4\% of words in notes). The second excerpt originates from Student 629's essay, which received the lowest total score (17/30); this student's notes are characterized by a high percentage of copied source language use (words copied with changes: $20 \%$, total words copied for all three categories: $60.4 \%$ ) and a low percentage of paraphrased notes (39.6\% of words in notes). These essays and student notes are, therefore, representative of the trend found in the statistical analysis. The excerpts illustrate two differences in the relationship between students' notes and the information and language used in the essay. First, the type of language that is copied as per our three coding categories (i.e., copied, copied with changes, and copied with gaps) differs: Student 663 mostly copied key terms or phrases from the sources into the notes, often from subheadings, such as "high prices," "high cost of distribution," and "excessive markup." In contrast, Student 629 copied more extensive phrases and even partial sentences from the source text. Second, the terms that Student 663 copied are integrated into the essay with original ideas that do not come from the source, such as "These high prices causes [sic] a reduction of the purchasing power of [the] individual." Student 629, on the other hand, copied more extensively from the source notes into the essay, and in the process transferred not only language copied from the source but also language errors from their own notes into the essay (e.g., "People with low self-esteem are not expect good perform"). This analysis of the two excerpts illustrates the nature of the relationship between a high degree of copied language use in the source notes and a low essay score. 
Table 5

Excerpts from High and Low Scoring Essay and Corresponding Notes

Essay excerpts
(Information from notes in bold)

Student notes

(Information used in essay in bold; information copied ${ }^{*}$ from source underlined)

1. We must acknowledge that marketing Marketing gathers $\neq$ feed backs but in has three main negative consequences. Firstly, the high prices to which products are sold is undeniable. A large part of this price arises from the marketing and advertising of the product. These high prices causes a reduction of the purchasing power of individual. This phenomenon trigger somehow poverty in our modern economies. Secondly, advertising is accused of deceptive practices which refers to the fact of claiming false characteristics about a product (2012). Thirdly, according to opponents of marketing, marketers use high pressure selling. It refers to pushing a consumer to buy a product that he doesn't need. We must recognize that those practices are amoral and that they shouldn't be use since they go against consumers rights. However, marketing is a very useful tool in our economy; it's used by every company and therefore, can't be blamed for what it does. general unfavorable because they could cheat on consumers by making them buy staff we don't need.

- High prices: high costs of distribution: too many intermediaries (unnecessary / duplicate services) $\neq$ to merges - and a good quality service.

- $\quad$ High advertising < promotion costs: heavy ad campaign + packaging < promotion' adds only psychological value. They pay to feel good.

- $\quad \neq$ maybe expensive but explains a quality of products and the brand's reputation.

- Excessive markups: high prices $\neq$ markets do not want high prices - they want to create a relationship between consumer \& brand.

- Deceptive practices: perceptive pricing / promotion / packaging (Student 663)

- High pressure selling: sales people make you buy stuff you don't need $\rightarrow$ short-term gain only. Can damage relationship between brand and customers 
2. Self-esteem can truly affect customer behaviour. People with low selfesteem are not expect good perform; meanwhile, people with high selfesteem have an opposite behaviour (Solomon, 2002). Solomon (2002) also shows a study that two groups of people, the first group are expose to beautiful women ads and the second group are not. As a result, the first group have lower satisfaction with their own appearance compare with the second group. Ideal self is shape by elements of consumer culture, and customers are please to purchase products that could achieve their ideal self or consistent with their actual self (Solomon, 2002). Accordingly, the gap between customer' ideal self and actual self could be smaller. (Student 629)
Low self-esteem, not expect good perform, try avoid embarrassment, failure, rejections. $\rightarrow$ high, contrast

Marketing communication influence level, exposure to ads trigger social-comparison. Evaluate themselves, compare ads $\rightarrow$ basic human motive.

Ads - change attitude by positive feeling $\rightarrow$ challenge consumer, show will provide remedy (conflict ideal / actual self).

Ideal self- shape by elements of consumer culture $\rightarrow$ purchase products to achieve (also consistent actual self)

Gap between ideal / actual self, larger for some consumers $\leftarrow$ good targets

Market communication employ fantasy attract attention.

Marketing strategies - consumer create vision of themselves by place in unfamiliar situation / permit to try interesting / challenging roles

* Copied includes all three coding categories for language use copied from the source: copied, copied with changes, and copied with gaps

\section{Discussion}

Our research question asked whether the level of linguistic modification to source language in EAP students' notes is associated with the overall quality of their source-based essays. The findings from this study suggest that there is indeed a relationship. The multiple linear regression indicated that more paraphrased and fewer copied with changes notes predicted better performance on the source-based essay writing task. The analysis of two essay excerpts provided further insight into the reasons behind this finding. Students with low percentage of copying tend to be strategic about which terms they copy, focusing on key terms from the source text, and these terms tend to be integrated well with the students' own ideas in the essay.

Previous research did not examine the language in source notes in the context of IWTs. However, studies have examined the degree to which source language use was modified in source-based essays and its relationship to writing performance, and their analysis yielded similar findings to ours in that higher levels of linguistic modifications and lower degrees of copying were associated with better performance on ITWs (Gebril \& Plakans, 2009, 2013; Plakans \& Gebril, 2013). There are two possible explanations for this finding in our study. The students who decide and/or are able to use more 
paraphrased language to write notes from sources might also be more likely to write better source-based essays. Alternatively, the fact that the notes contain less language derived from the source allows L2 writers to write better essays. In other words, we do not know why Student 633, whose essay and notes we analyzed above, copied only strategic phrases from the source into their notes. Did the student simply follow the instructions on the notetaking template (see Appendix A), which told students to "write phrases in your own words to convey the important points"? Alternatively, did the student have a better understanding of the essay genre and/or comprehend the source texts better, as an anonymous reviewer asked? We do not have data to answer these questions. However, based on the data from the current study, note quality in source-based writing is worthy of investigation, and including additional independent variables of genre knowledge and source text comprehension in the research design of future studies of source notes in the context of IWTs would be advantageous.

Previous research on planning or note-taking had not examined the quality of source notes. However, that line of research revealed a link between writing practices encouraged by L2 writing teachers and impacts on students' writing quality. First, writing teachers generally encourage their students to plan their texts before students start writing because it is believed that this will lead to higher quality texts. Research on writing plans and the relationship to text quality revealed support for this practice: more elaborated writing plans and more ideas generated prior to writing are associated with measures of writing quality (Abrams \& Byrd, 2016; Chai, 2006; Joaquin et al., 2016). Although our study focused on a different aspect of students' prewriting notes, it too provides evidence to support practices encouraged by teachers in L2 writing classes. In L2 writing pedagogy for source-based writing, students are encouraged to transform language used in source texts and use their own words as they take notes (e.g., see Douglas, 2018 or the EAP program note-taking template in Appendix A) or to reflect on whether to paraphrase, summarize, or quote source information in their notes (Leu \& Neumann, 2017). Our study provides evidence to support this practice because students who paraphrased source language in their notes and used their own words to record the source information obtained higher scores on their essays. The current study, therefore, provides evidence for what Ojima (2006) had intuited: Students' differing prewriting preparation does indeed have an impact on the quality of the written texts they produced.

This study has implications for L2 writing pedagogy in source-based academic writing programs. It provides evidence for the importance that these programs generally place on paraphrasing skills. Not only are these skills required for the integration of source information into students' texts; the current study provides evidence that even at the note-taking stage paraphrasing skills provide students with a significant advantage because they obtain higher scores on their writing. This study also supports the practice 
in EAP programs of emphasizing note-taking strategies that require source language transformation at both the essay-writing and note-taking stages. To our knowledge, our study is the first to examine this issue and therefore makes an important contribution in this regard. Our study did not examine which conditions or factors allow students to produce better paraphrases, and how that might be linked to source text comprehension or understanding what is involved in writing a source-based essay. We focused simply on the relationship between the level of paraphrasing in students' notes and the overall quality of their essays. However, there is evidence in other research that a focus on source comprehension and the language repertoire needed to paraphrase that information appropriately does lead to more appropriate source use, which includes better paraphrasing and less patchwriting (Neumann et al., in press).

The present study has two important limitations. Our findings reveal a positive relationship between the level of paraphrased language use in students' notes and the quality of their essays. However, we are not able to determine based on our data whether the students who transformed the source language and used their own words were able to do so because they had higher English language proficiency levels than the students who relied more on copying source language use into their source notes or whether students with higher essay scores simply had better note-taking strategies. Future research on source notes quality should consider including independent measures of English language proficiency to determine whether this variable has an intervening force on the relationship between the quality of students' source notes and the resulting source-based essays. Second, our design did not include independent measures of source text comprehension. Although there is evidence in previous research that lower comprehension is associated with higher degrees of patchwriting (Asención Delaney, 2008; Esmaeili, 2002; Plakans, 2009a; Sawaki et al., 2013), our data do not allow us to make a connection between the level of source use comprehension, the quality of source notes, and essay quality. Investigating the relationship between these three variables would, however, be an important and promising avenue for future research.

\section{Notes}

1. As part of our data collection, we only observed some lessons of certain groups of the course and interviewed some of the instructors; for that reasons, we can only provide this general description of note-taking instruction.

\section{Acknowledgement}

The research was funded through an Insight Development Grant from the Social Sciences and Humanities Research Council (SSHRC, grant number 403-2016-00099) to the first three authors. We would like to thank Nina Padden, Sarah Loubiri, and our research assistants Helene Bramwell, Libing Lu, Nora Sargent, and William Zullo. 


\section{The Authors}

Heike Neumann is a senior lecturer of English as a second language and a language test developer in the Department of Education at Concordia University in Montreal, Quebec, Canada. Her research focuses on second language writing pedagogy, English for academic purposes, and language assessment.

Sarah Leu is the director of language and intercultural communication in the School of Continuing Studies at McGill University. Her research interests include genre approaches to writing instruction for L2 students and feedback on writing. She has published in the Journal of Second Language Writing and Writing Center Journal.

Kim McDonough is a professor of applied linguistics and Canada research chair in the Department of Education and the Centre for the Study of Learning and Performance at Concordia University. Her research interests include second language acquisition, joint attention, peer interaction, and collaborative writing.

Leslie Gil has an MA in applied linguistics at Concordia University in Montreal, Quebec, Canada. Her research interests include second language pedagogy, bimodal language acquisition, language assessment, and corrective feedback.

Bonnie Crawford is an editor and online ESL/EFL teacher in Montreal, Quebec, Canada. Her research interests include second language acquisition, professional and academic writing, and unintentional plagiarism.

\section{References}

Abrams, Z. I., \& Byrd, D. R. (2016). The effects of pre-task planning on L2 writing: Mind-mapping and chronological sequencing in a 1st-year German class. System, 63, 1-12. https://doi. org/10.1016/j.system.2016.08.011

Armstrong, G., Kotler, P., Trifts, V., \& Buchwitz, L. A. (2012). Marketing: An introduction (4th ed.). Pearson Education Canada.

Asención Delaney, Y. (2008). Investigating the reading-to-write construct. Journal of English for Academic Purposes, 7(3), 140-150. http://dx.doi.org/10.1016/j.jeap.2008.04.001

Chai, C. (2006). Writing plan quality: Relevance to writing scores. Assessing Writing, 11(3), 198-223. https://doi.org/10.1016/j.asw.2007.01.001

Cumming, A. (2013). Assessing integrated writing tasks for academic purposes: Promises and perils. Language Assessment Quarterly, 10(1), 1-8. https://doi.org/10.1080/15434303.2011.622016

Cumming, A., Lai, C., \& Cho, H. (2016). Students' writing from sources for academic purposes: A synthesis of recent research. Journal of English for Academic Purposes, 23, 47-58. https://doi. org/10.1016/j.jeap.2016.06.002

Currie, P. (1998). Staying out of trouble: Apparent plagiarism and academic survival. Journal of Second Language Writing, 7(1), 1-18. https://doi.org/10.1016/S1060-3743(98)90003-0

Davis, M. (2013). The development of source use by international postgraduate students. Journal of English for Academic Purposes, 12(2), 125-135. https://doi.org/10.1016/j.jeap.2012.11.008

Douglas, S. R. (2018). Academic inquiry 4: Essays and research (2nd ed.). Oxford University Press.

Esmaeili, H. (2002). Integrated reading and writing tasks and ESL students' reading and writing performance in an English language test. Canadian Modern Language Review, 58(4), 599-622.

Flowerdew, J., \& Li, Y. (2007). Language re-use among Chinese apprentice scientists writing for publication. Applied Linguistics, 28(3), 440-465. https://doi.org/10.1093/applin/amm031

Foroughi, C. K., Werner, N. E., Nelson, E. T., \& Boehm-Davis, D. A. (2014). Do interruptions affect quality of work? Human Factors, 56(7), 1262-1271. https://doi.org/10.1177/0018720814531786

Gebril, A., \& Plakans, L. (2009). Investigating source use, discourse features, and process in inte- 
grated writing tests. Spaan Working Papers in Second or Foreign Language Assessment, 7, 47-84. https://michiganassessment.org/wp-content/uploads/2014/12/Spaan_V7_FULL.pdf

Gebril, A., \& Plakans, L. (2013). Toward a transparent construct of reading-to-write tasks: The interface between discourse features and proficiency. Language Assessment Quarterly, 10(1), 9-27. https://doi.org/10.1080/15434303.2011.642040

Howard, R. M. (1992). A plagiarism pentimento. Journal of Teaching Writing, 11(2), 233-245. http:// journals.iupui.edu/index.php/teachingwriting/article/view/1116/1088

Howard, R. M., Serviss, T., \& Rodrigue, T. K. (2010). Writing from sources, writing from sentences. Writing \& Pedagogy, 2(2), 177-192. https://doi.org/10.1558/wap.v2i2.177

Joaquin, A. D. L., Kim, S. H., \& Shin, S.-Y. (2016). Examining prewriting strategies in L2 writing: Do they really work? Asian EFL Journal, 15(2), 156-189. https://www.elejournals. com/1379/2016/asian-efl-journal/the-asian-efl-journal-quarterly-june-2016/

Johnson, M. D., Mercado, L., \& Acevedo, A. (2012). The effect of planning sub-processes on L2 writing fluency, grammatical complexity, and lexical complexity. Journal of Second Language Writing, 21(3), 264-282. https://doi.org/10.1016/j.jslw.2012.05.011

Kellogg, R. T. (1990). Effectivenss of prewriting strategies as a function of task demands. The American Journal of Psychology, 103(3), 327-342.

Leu, S., \& Neumann, H. (2017). Academic inquiry 3: Essays and integrating sources (1st ed.). Oxford University Press.

Li, Y., \& Casanave, C. P. (2012). Two first-year students' strategies for writing from sources: Patchwriting or plagiarism? Journal of Second Language Writing, 21(2), 165-180. https://doi. org/10.1016/j.jslw.2012.03.002

Limpo, T., \& Alves, R. A. (2018). Effects of planning strategies on writing dynamics and final texts. Acta Psychologica, 188, 97-109. https://doi.org/https://doi.org/10.1016/j.actpsy.2018.06.001

Liu, P.-L. (2011). A study on the use of computerized concept mapping to assist ESL learners' writing. Computers \& Education, 57(4), 2548-2558. https://doi.org/10.1016/j.compedu.2011.03.015

McCulloch, S. (2013). Investigating the reading-to-write processes and source use of L2 postgraduate students in real-life academic tasks: An exploratory study. Journal of English for Academic Purposes, 12(2), 136-147. https://doi.org/10.1016/j.jeap.2012.11.009

Neumann, H., Leu, S., \& McDonough, K. (2019). L2 writers' use of outside sources and the related challenges. Journal of English for Academic Purposes, 38, 106-120. https://doi.org/10.1016/j. jeap.2019.02.002

Neumann, H., Leu, S., McDonough, K., \& Crawford, B. (in press). Improving students' source integration skills: Does a focus on reading comprehension and vocabulary development work? Journal of English for Academic Purposes. https://doi.org/10.1016/j.jeap.2020.100909

Ojima, M. (2006). Concept mapping as pre-task planning: A case study of three Japanese ESL writers. System, 34(4), 566-585. https://doi.org/10.1016/j.system.2006.08.003

Ong, J. (2014). How do planning time and task conditions affect metacognitive processes of L2 writers? Journal of Second Language Writing, 23, 17-30. https://doi.org/10.1016/j.jslw.2013.10.002

Ong, J., \& Zhang, L. J. (2010). Effects of task complexity on the fluency and lexical complexity in EFL students' argumentative writing. Journal of Second Language Writing, 19(4), 218-233. https://doi.org/10.1016/j.jslw.2010.10.003

Payant, C., McDonough, K., Uludag, P., \& Lindberg, R. (2019). Predicting integrated writing task performance: Source comprehension, prewriting planning, and individual differences. Journal of English for Academic Purposes, 40, 87-97. https://doi.org/10.1016/j.jeap.2019.06.001

Pecorari, D. (2003). Good and original: Plagiarism and patchwriting in academic second-language writing. Journal of Second Language Writing, 12(4), 317-345. https://doi.org/10.1016/j. jslw.2003.08.004

Pecorari, D. (2006). Visible and occluded citation features in postgraduate second-language writing [Article]. English for Specific Purposes, 25(1), 4-29. https://doi.org/10.1016/j.esp.2005.04.004

Pecorari, D. (2010). Academic writing and plagiarism: A linguistic analysis. Continuum.

Pecorari, D. (2013). Teaching to avoid plagiarism: How to promote good source use. Open University Press. 
Plakans, L. (2008). Comparing composing processes in writing-only and reading-to-write test tasks. Assessing Writing, 13(2), 111-129. https://doi.org/10.1016/j.asw.2008.07.001

Plakans, L. (2009a). Discourse synthesis in integrated second language writing assessment. Language Testing, 26(4), 561-587. https://doi.org/10.1177/0265532209340192

Plakans, L. (2009b). The role of reading strategies in integrated L2 writing tasks. Journal of English for Academic Purposes, 8(4), 252-266. https://doi.org/10.1016/j.jeap.2009.05.001

Plakans, L., \& Gebril, A. (2012). A close investigation into source use in integrated second language writing tasks. Assessing Writing, 17(1), 18-34. https://doi.org/10.1016/j.asw.2011.09.002

Plakans, L., \& Gebril, A. (2013). Using multiple texts in an integrated writing assessment: Source text use as a predictor of score. Journal of Second Language Writing, 22(3), 217-230. https://doi. org/10.1016/j.jslw.2013.02.003

Plonsky, L., \& Oswald, F. L. (2014). How big is "big"? Interpreting effect sizes in L2 research. Language Learning, 64(4), 878-912. https://doi.org/10.1111/lang.12079

Sandel, M. J. (2012, April). What isn't for sale. The Atlantic. https://www.theatlantic.com/magazine/ archive/2012/04/what-isnt-for-sale/308902/

Sawaki, Y., Quinlan, T., \& Lee, Y.-W. (2013). Understanding learner strengths and weaknesses: Assessing performance on an integrated writing task. Language Assessment Quarterly, 10(1), 73-95. https://doi.org/10.1080/15434303.2011.633305

Schmitt, D., \& Schmitt, N. (2005). Focus on vocabulary: Mastering the academic word list. Longman.

Solomon, M., Bamossy, G., \& Askegaard, S. (2002). Consumer behaviour: A European perspective. Prentice Hall Europe.

Weigle, S. C., \& Parker, K. (2012). Source text borrowing in an integrated reading/writing assessment. Journal of Second Language Writing, 21(2), 118-133. https://doi.org/10.1016/j. jslw.2012.03.004

Wette, R. (2010). Evaluating student learning in a university-level EAP unit on writing using sources. Journal of Second Language Writing, 19(3), 158-177. https://doi.org/10.1016/j. jslw.2010.06.002

Williams, J. (2012). Learning English for academic purposes: Reading and writing (2nd ed.). ERPI.

Wolfersberger, M. (2013). Refining the construct of classroom-based writing-from-readings assessment: The role of task representation. Language Assessment Quarterly, 10(1), 49-72. https://doi. org/10.1080/15434303.2012.750661 


\section{Appendix A: Note-Taking Template}

\begin{tabular}{|l|l|}
\hline Your name: & \multicolumn{1}{|c|}{ Your ID number: } \\
\hline & Writing Res ource She S \\
\hline $\begin{array}{l}\text { Source } \\
\text { Information: }\end{array}$ & \\
\hline
\end{tabular}

\begin{tabular}{|l|l|}
\hline Vocabulary: & \\
New words, key & \\
words in text, & \\
collocation & \\
information & \\
\hline
\end{tabular}

\section{Main Idea:}

State the main

idea of the text in

your own words

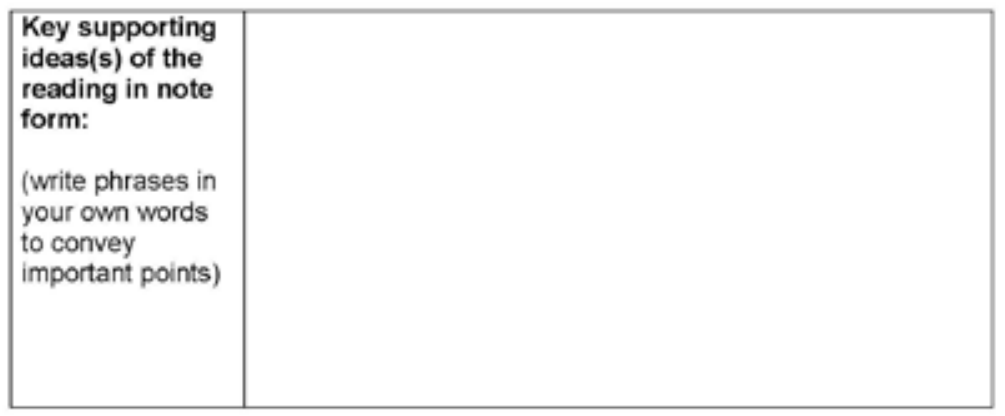

\section{Quotations}

(optional): Nete unique

perases which demonstrate

the autnor's antitude or help

to emphasice a point you've

made

Only this resource sheet may be used in the Midterm 2 and Final exams. The sheet may not be resized, enlarged, or otherwise altered. Only one sheet per source may be used. Handwritten notes in pen must fit within the boxes. Notes not entered onto this sheet will not be permitted in exams. 


\section{Appendix B: Rating Scale}

\begin{tabular}{|c|c|c|}
\hline Cor & nt \& Organization & Grammar \& Vocabulary \\
\hline 10 & $\begin{array}{l}\text { C thesis (explicit or implicit) and topic sentences } \\
\text { express the writer's position on the assigned topic in } \\
\text { a clear and sophisticated way } \\
\text { C informative, convincing and relevant supporting } \\
\text { ideas } \\
\text { C information from sources accurately interpreted and } \\
\text { acknowledged } \\
\text { C exemplary selection and integration of source } \\
\text { material } \\
\text { C acknowledgment of and response to opposing } \\
\text { view(s) is thorough and effective } \\
\text { O clarity of message enhanced by clear pattern of } \\
\text { organization between and within paragraphs } \\
\text { O effective and varied transitions between ideas }\end{array}$ & $\begin{array}{l}\text { G variety of sentence } \\
\text { structures used with no } \\
\text { major sentence problems } \\
\text { G rare minor language } \\
\text { errors } \\
\text { V sophisticated and precise } \\
\text { word choice and accurate } \\
\text { word form } \\
\mathbf{V} \text { extensive range and } \\
\text { variety of vocabulary }\end{array}$ \\
\hline 7 & $\begin{array}{l}\text { C thesis (explicit or implicit) takes a clear position on } \\
\text { the assigned topic; topic sentences identifiable and } \\
\text { relevant } \\
\text { C supporting ideas are mostly sufficiently developed } \\
\text { C most information from sources is accurately } \\
\text { interpreted and acknowledged } \\
\text { C mostly effective selection and integration of source } \\
\text { material } \\
\text { C mostly effective acknowledgment of and response } \\
\text { to at least one opposing view } \\
\text { O mostly logical sequencing of ideas and smooth } \\
\text { transitions between and within paragraphs }\end{array}$ & $\begin{array}{l}\text { G variety of sentence } \\
\text { structures used with rare } \\
\text { major sentence problems } \\
\text { G occasional minor } \\
\text { language errors } \\
\text { V mostly accurate and } \\
\text { appropriate word choice and } \\
\text { form } \\
\text { V adequate range and } \\
\text { variety of vocabulary }\end{array}$ \\
\hline
\end{tabular}




\begin{tabular}{|c|c|c|}
\hline 5 & $\begin{array}{l}\text { C thesis and topic sentences identifiable, but weak; } \\
\text { e.g., vague, narrow, or not argumentative } \\
\text { C some supporting ideas are inadequately } \\
\text { developed, irrelevant, and/or repetitive } \\
\text { C some information from sources is misinterpreted } \\
\text { and/or unacknowledged } \\
\text { C ineffective selection and integration of source } \\
\text { material } \\
\text { C acknowledgement of opposing view(s) is present } \\
\text { but unclear, insufficient, or not coherently integrated } \\
\text { O significant problem(s) with principles of essay } \\
\text { organization } \\
\text { O relationship between ideas is poorly established } \\
\text { between and/or within paragraphs; transitions } \\
\text { sometimes not smooth }\end{array}$ & $\begin{array}{l}\text { G major sentence problems } \\
\text { or limited sentence variety } \\
\text { G frequent minor language } \\
\text { errors } \\
\mathbf{V} \text { imprecise word choice or } \\
\text { frequent word form errors } \\
\mathbf{V} \text { limited range and variety } \\
\text { of vocabulary }\end{array}$ \\
\hline 4 & $\begin{array}{l}\text { C thesis and topic sentences missing, irrelevant, or } \\
\text { incomprehensible } \\
\text { C supporting points are inadequately developed, } \\
\text { irrelevant, unconvincing and/or repetitive } \\
\text { C little or no information from sources used } \\
\text { C relies on lengthy direct quotations; sentences } \\
\text { or sections of text copied or copied directly from } \\
\text { resource sheets } \\
\text { C no acknowledgment of opposing views in argument } \\
\text { O no clear pattern of organization } \\
\text { O sequence of ideas not logical or coherent; poor or } \\
\text { absent transitions between ideas } \\
\mathbf{X} \text { insufficient information for evaluation }\end{array}$ & $\begin{array}{l}\text { G frequent major sentence } \\
\text { structure problems; lack of } \\
\text { sentence variety } \\
\text { G pervasive or severe errors } \\
\text { impede comprehension of } \\
\text { ideas } \\
\text { V limited and inaccurate } \\
\text { word choice interferes with } \\
\text { meaning; pervasive word } \\
\text { form errors } \\
\text { V very narrow range of } \\
\text { vocabulary }\end{array}$ \\
\hline
\end{tabular}

Content (C): _ / 10

Organization (O): $/ 10$

Grammar (G) \& Vocabulary (V): $/ 10$

Total Score: /30 